Peer Reviewed Journal

Young Scholar's Contribution

\title{
EFFECTS OF WORK PLACE DESIGN ON BEHAVIORS
}

\author{
Madiha Salam*
}

\begin{abstract}
Nowadays people spend most of their time inside an enveloped building, their thoughts molded by the walls. In the eagerness of running with time the capitalist minds have forced humans to live like a machine which has resulted in much distress and mental tension as a part and parcel. So today, an average office worker has less productivity at the workplace and he/she comes home carrying the burden of work, which can hypothetically be improved by designing better spaces. Good architecture can heal a person and develop positive attributes in him/her. To be an architect with moral values, one must have deep appreciation of a human lifestyle and its capacity to adapt from its surroundings. This paper focuses on workplace environment and spaces in Karachi, considering the question how different spaces influence cognition? And is there an ideal architectural space for various kinds of thinking? The paper considers antiquity of the architectural determinism as a theory, and works upon the attributes which can diverge and positively enhance architectural perseverance through the review of archival data, articles, books and historical reference with support of questionnaires. The conclusion points towards the need of architecture to be developed into not just an envelope, but as a space which shapes the behavior, attribute and positivity of its users.
\end{abstract}

Keywords: Architecture and behaviours, Cognitive architecture, work place environment.

\section{INTRODUCTION}

It is a well-known fact that the environment impacts on our mood and health. Aesthetically improved, psychologically designed spaces effect our disposition and vigor. Since the surrounding is readily taken for granted, it can influence us very powerfully. Every single space one breathes in matters, whether one designs the spaces to have positive effect, or designs them haphazardly, can effect adversely on the health, mind and ultimately the soul. This makes architecture a potentially dangerous tool to manipulate people. One must aim to design constructive spaces that not only are comfort zones, but have long-lasting effect and people feel relaxed not only in their work place but also when they go home.

Most of the office designs in Karachi are cramped spaces with necessary office furniture and basic requirements with barely any space to move around. These spaces are very rarely well ventilated or have access to day light. The imbalance has lead to an alarming situation where employees are suffering from frustration, depression and mental agony. Internationally the office spaces are more focused on how to magnetically attract more money, seeing the short-term advantages, than on how to give more comfort to the employees and make them more productive for longterm gains. In researches (Alker, 2014) it is proven that the design of a space effects the general behavior of the human being and its constant contact makes a lasting psychological effect. An office space can have a negative effect on the office worker and he/she can become stressed and the productivity can be impacted. This research looks into the possibility to formulate better designed office spaces with comfortable environment leading to increase in the productivity of an average office worker and in helping to bring the average stress levels down. By experiencing better designed spaces on a daily basis the workers will become less frustrated, feel more comfortable in their office spaces and will have an overall positive impact on their after-office life. The main research question outlined for this research is what role does an office environment play in shaping the behavior and the productivity of its users?

The aim of the research is to take stock of the existing situation of workplace spaces in the city of Karachi and to focus on how environmentally responsive

* Madiha Salam, Lecturer, Department of Architecture and Planning, NED University, Karachi.

Email correspondence: madiha_salam@ymail.com

Journal of Research in Architecture and Planning: Vol. 25, 2018 (Second Issue) 
architectural spaces can be salubrious and bring change in behaviors, attributes and positivity of its users.

\section{LITERATURE REVIEW}

Archival data, journals, books and historical references have been used as secondary sources of information. The literature review is divided into three major headings: architectural determinism, effects of work place environment on people and fundamental concepts of person-built environment relationship.

For architects and designers, the awareness that built environment influences health, wellbeing and productivity of their inhabitants is not new. Studies demonstrate that poor air quality and lighting intensifies the number of sick days and can affect sleep, but the evidence is still not persuasive enough for most of the design, financing and leasing choices. Good indoor air quality, thermal comfort, high quality views, daylight, good acoustics and indeed location and amenities - all play a crucial role in creating a healthy, productive workplace. The connection between individuals and buildings in which people are employed is vital. Most of the businesses are missing the trick in overlooking the massive prospects that this relationship can bring. This literature review circulates around all the ideas which incur the knowledge on the subject and the impact of a well-designed space on office workers.

\section{Architectural Determinism}

Architectural Determinism is a social theory which states that all human behavior can be derived in relation to one's environment. Many sociologists and architects claim that the built environment is accountable for all human connections, some discard this theory by claiming it as superfluous and something that glorifies the role of an architect, and others believe that architecture is a tributary that influences social and cultural history. Architects and theorists over time have been very vigilant about the impacts on behaviors of the environment. This theory was supported by architect Leon Battista Alberti, who claimed that a balanced Classical form can even compel the most aggressive invaders to put down their arms and become more civilized. Later architect Frank Lloyd Wright, in early 19th century, supported this theory by stating that most corruption can be easily curtailed by appropriate architecture and people can turn to wholesome activities. Similarly, Sir Ebenezer Howard in 1898, forced upon

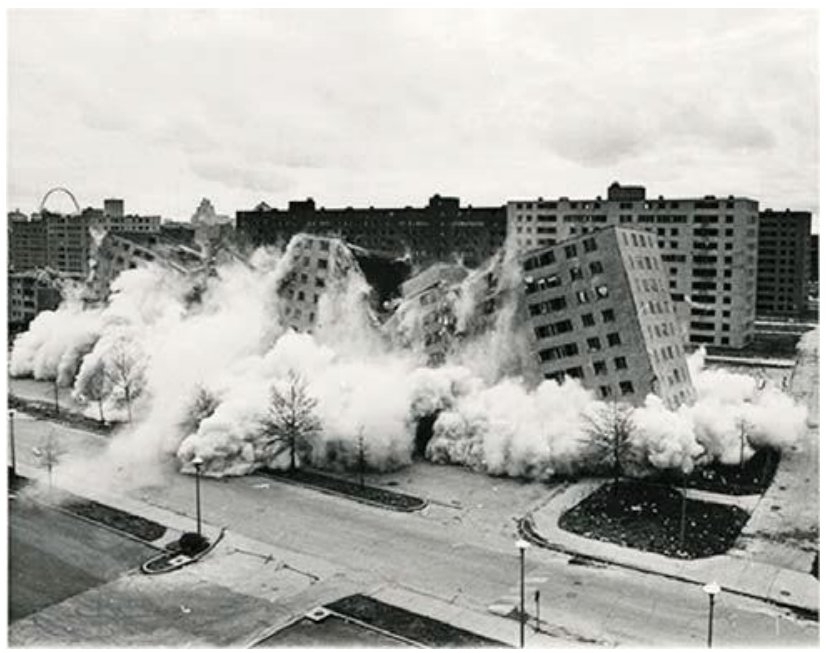

Figure 1: The demolition of Pruitt-Igoe in 1972 fueled resistance to deterministic thinking (Golembiewski, 2014).

his opinion that for the companies to be more efficient the employees should be living in village like garden communities. Interestingly, it took a lengthy list of failures over the millennia, before theorists took to critiquing architectural fantasy with nasty reprisals of Modernism. They believed just the opposite and focused more on the celebration of form, such that at the highpoint of this inclination was the delight shared over the demolition of the famously dangerous and dysfunctional urban housing complex in St Louis in the US, which was initially the epitome of modern architectural determinism and was made on a very strong concept of how the urban living designs, community interactions and enclosed playyards amongst the lower income groups can help in reducing criminal activities (figure 1). In reality this served in reverse and became the hotspot for crime and poverty (Marmot, 2002).

According to sociologist William Cameron, the physical forms in many cases can limit, permit or determine the kind of activities that one can be engaged in, thus a designed office administration must consider that the built environments may increase the productivity of a worker (Cameron, 1963). This can be done by creating a communicative environment and letting people meet each other more often. It is difficult to ascertain whether architectural determinism is evident in this manner; the effect on workers' productivity may stem from the newness of the environment inspiring one to work, or 
the fact that workers feel appreciated by the management to improve their surroundings that drive their work (Marmot, 2002).

Although the environment may influence some behavior, it is not the chief factor influencing social interactions. Another sociologist Alice Coleman agrees with this statement to some extent. Coleman conducted an extensive study of a housing estate in Clover Hill, in Rochdale, England and found many links between the atmosphere of "social malaise" and crime rates, and the conditions of the built environment. According to Marmot, "Environmental determinism is a concept that is too simplified to describe the complex relationships between individuals and their physical, social, and psychological world" (Marmot, 2002: 253). Some aspects of the built environment make human interactions or attitudes more likely to occur, but do not govern them. Despite this, architects, planners and designers still must consider the physical and psychological impact of their building designs, if they are to positively contribute to the daily lives of human beings and keep them safe from stress and frustrations, experienced commonly today.

\section{Effects of work place environment on people}

The efficiency of staff, or anything that distresses their capability to be prolific, should be a major concern for any employer, and therefore the building design in which they function, should be the key focus. Concentrating on the office sector, it can be stated that the physical work environment has a direct impact on the health and productivity of the office workers. Health includes physical and mental health, wellbeing includes broader feelings or perceptions of satisfaction and happiness, and productivity denotes more explicitly to business-oriented outputs. For example, a meta-analysis in 2006 of twenty four trainings found that deprived air quality sank performance by up to ten percent, such as typing speed. Short term sick leave has also been found to be thirty five percent lower in offices ventilated with greater supply rates of outdoor air. A research in 2006 on thermal comfort indicated a ten percent reduction in performance at both $30^{\circ} \mathrm{C}$ and $15^{\circ} \mathrm{C}$, compared with a baseline between $21^{\circ} \mathrm{C}$ and $23^{\circ} \mathrm{C}$. And in terms of lighting, another, which investigated the relationship between view quality, daylighting and sick leave of employees in administration offices of Northwest University, Washington, found those in offices with better daylight and views took six percent

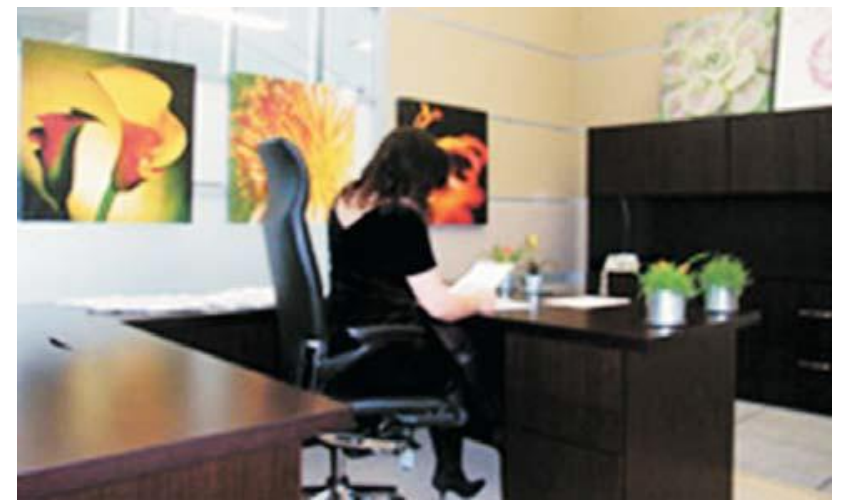

Figure 2: Working in a decorated office can promote happiness and help people concentrate on the task at hand (Haslam, 2010).

fewer sick days (Haslam, 2010) (figure 2). Neuroscientists have also concluded that workers with offices that have windows which receive more daylight exposure during work hours sleep an average of forty six minutes more per night and are more relaxed. If daylight access to windows is maximized, it not only reduces the need for electric lighting, it also improves productivity and even workers' sleeping patterns. Even if people are given more personal control over temperature it typically makes them happier, while also saving energy (Alker, 2014).

According to another research, most of the presentday offices offer very little user control, but studies suggest this practice needs to be challenged. When people sense uncomfortability in their environs they are less involved, not only with the space but also with what they do in it. If they are given some control, this behaviour changes and people report being happier at work, relating more with their employer, and are more effective when doing their jobs.

Another study suggested that participants take on a series of tasks in a workspace that are either lean (bare and functional), enriched (decorated with plants and pictures), empowered (allowing the individual to design the area) or disempowered (where the individual's design was redesigned by a 'manager'). According to the literature review people working in enriched spaces were seventeen percent more productive than those in lean spaces, but those sitting at empowered desks were even more efficient - being thirty two percent more productive than their lean counterparts without any increase in errors (Haslam, 2010). 


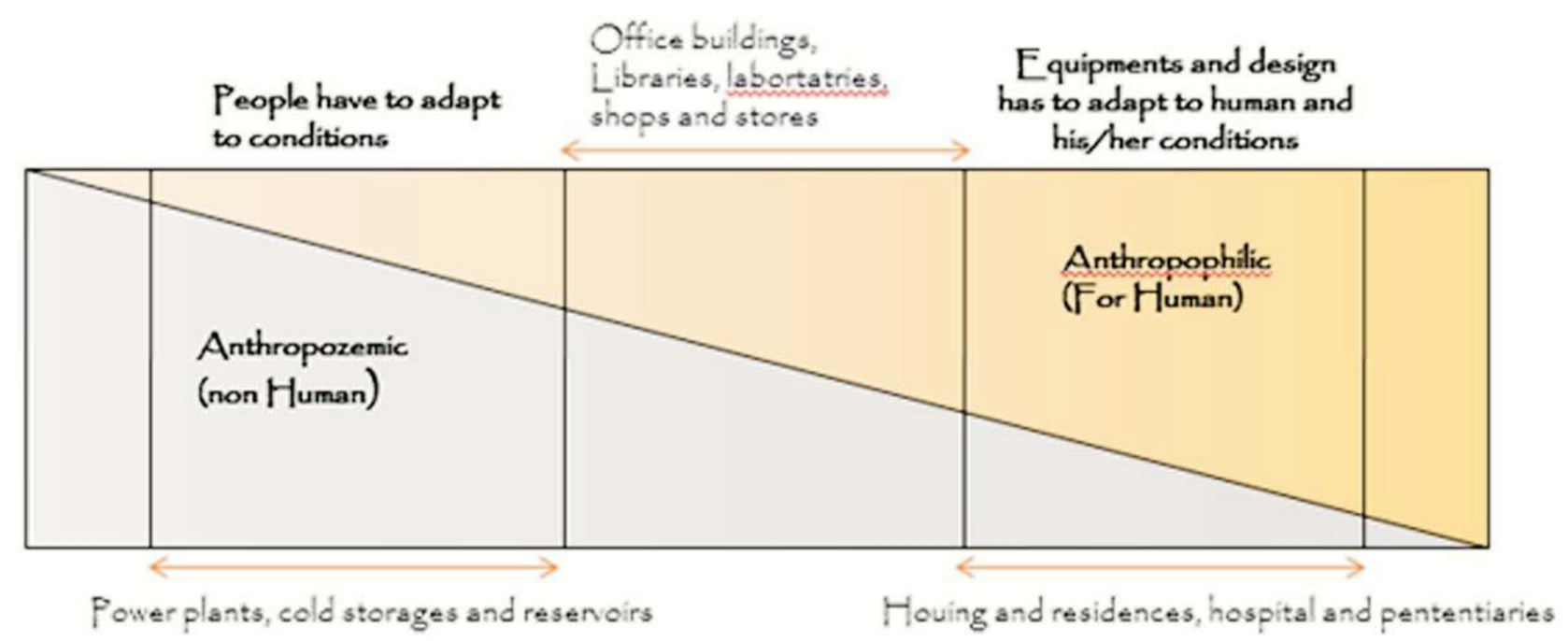

Figure 3: The concept of Competence (Lang, 1987).

Thus, it is the need of time to recognize the potential improvements that can be made by handing some control of space over to workers and thereby giving them an opportunity to realize their own identity in the workplace. Not only does office design determine simple things like whether people's backs ache, it has the potential to affect how much they accomplish, how much initiative they take, and their overall professional satisfaction.

\section{Fundamental Concepts of Person-Built Environment Relationship}

Lang (1987), suggests that some buildings are designed more for the successful functioning of machines and equipment than for the people who run them. In other buildings, the needs of people are paramount (figure $3)$. He labels the former type as "anthropozemic buildings" and the latter type as "anthropophilic." In anthropozemic buildings people adapt to the conditions, in anthropophilic buildings the equipment has to be adapted to the conditions of people (Lang, 1987).

An environment can be considered to consist of interrelated geographic, built, social and cultural components that contribute to certain behaviors in consistent ways. The set of affordances of the environment at a location constitutes the potential environment for human behavior at that place. Not all these affordances are perceived by people involved. Each individual has a variety of competencies in dealing with different aspects of the built environment. Some of these aspects are physiological and some are social and some are cultural. These differences affect the way the environment is perceived, the images people have of it and the way it can be and is used. The environment in which people socialize shapes competencies, because what one knows and what one learns to look at is shaped by what the environment offers. It is possible for people to be able to perceive the affordances of the environment for others, while being unable to use these affordances themselves, because they do not have the competence to do so, or because cultural pressures prevent them from doing so or because they lack resources in money or time. Attitudes may change because of factors within the person. An important factor here is the principle of cognitive consistency. This theory starts from the idea that one seeks consistency in one's belief and attitude in any situation where two cognitions are inconsistent (McLeod, 2014).

Even though an environment impacts on the set of behaviors, this does not mean that the behaviors will take place, even though people perceive the affordances and are component enough to use them. On the other hand, if the affordances are not there, the behavior cannot take place. The environment can be adapted to afford the desired behavior, or else the people concerned may adapt their behavior to cope with the environment as it is. These adaptations may be accompanied by physiological or psychological stress. This particularly 


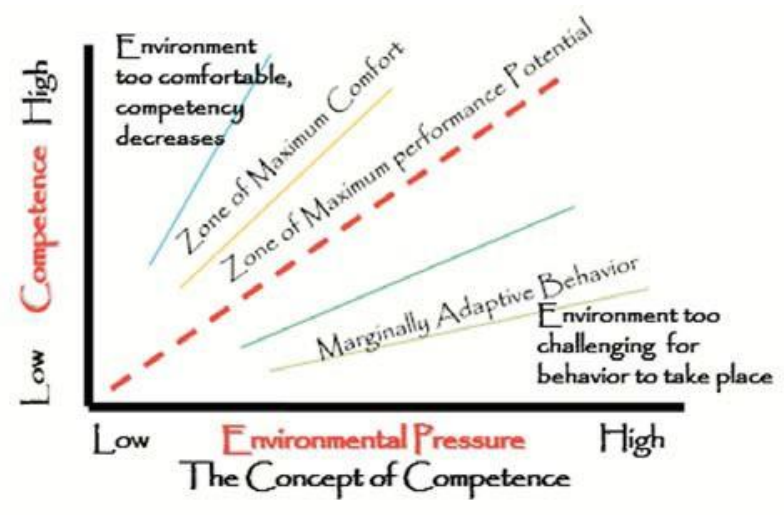

Figure 4: The concept of competence (Lang, 1987).

occurs, as dissonance theory explains, when people are in situations that are not self-chosen. The role of architectural environment is thus accommodative and not deterministic except in a negative sense; if the built environment does not encourage the behavior, the behavior cannot take place (figures 4 and 5) (Saarinen, 1976).

A building design impinges on people's lives through the affordances it possesses. It cannot be assumed, simply because the environment contains a set of affordances for the activities for policymakers or designers. Not all people perceive the affordances of the environment in the same way.

Effective environment is different for different people. If the differences occur haphazardly, then the conclusion one would reach is that all that can be achieved through design is to allow some behaviors and to exclude others a purely possibility stance. Behavior does not however, occur haphazardly. It has certain predictability. It is possible to make predictions, but who will use what facility, who will bother to look at which architectural composition, and who will respond to spaces warmly and who will not respond at all can only be predicted without much certainty.

\section{Research Methodology}

Quantitative interviews were conducted with thirty five office going people in Karachi, to find out the pattern of office life that people have and what type of behavioral changes they are enduring because of office environment. The effect of office design on mental health, psychological and physical needs was also

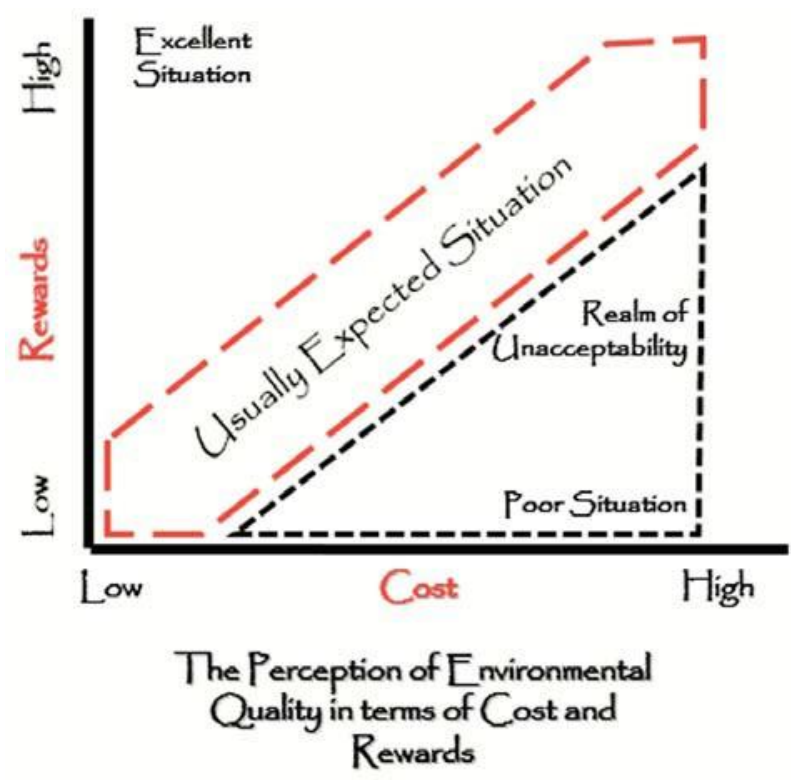

Figure 5: Perception of Environmental Quality (Lang, 1987).

investigated. The questionnaires were made on google forms and were filled online, and were limited to the office workers of Karachi. The questionnaires were answered by thirty five individuals working in different types of Karachi's offices. The questions asked were related to office design, ergonomics, thermal controls in the office, relations with the colleagues and management, and the way people commute from their house to their office and back. Questions mostly focused on how the above-mentioned aspects impacted on the behavioral changes in people. It was made sure that the questions covered all types of queries that generally depict the moods of office workers and how their surroundings affect them. Questions regarding the after-work life and the behaviors after work were also made part of this exercise. The collected data was analyzed using quantitative analysis and was put together in the form of pie charts, whereas the explanations and the qualitative analysis were also done in detail.

\section{Initial observations through informal interviews}

Common observations deduced from the research were that almost all the people who work in offices in Karachi suffer from frustration, stress and anxiety. This data was gathered from questionnaires as well as through three informal interviews from people who 
are inhabitants of Karachi and work within the city. The hypothesis, that normally everyone who goes to work in the vicinity of Karachi is bound to have a higher stress and frustration level than the other cities of Pakistan, was made. The reasons behind the stress are variant but mostly revolve around the design incapabilities of the workplaces. Office spaces have no concern for the comfort and mental relaxation of the workers. The focus is just on earning money, thus expensive equipment, which is the liability of the company, is given much more importance and comfort than the people working in that space. Most of the businesses focus on short-term feasibilities and are not concerned about the long-term goals. This is the reality of most of the offices in Karachi and users are forced to accept this situation as the unemployment rates are high. The irony is that even the architectural firms mostly work in small cramped spaces or small houses are utilized for the purpose of giving more space to the plotter, desktop systems and furniture, then the person working there. Over all, these spaces mostly do not see the daylight and are either ventilated through air-conditioning or are suffocated with almost no proper cross ventilation. On the contrary, it is observed that few spaces which are designed properly and make the users comfortable have been more productive not in terms of the business but in the long run positive behavioral changes of the employees. Secondly these people have a better after office life, and are more productive and healthy, as the employees do not suffer from after work stresses.

\section{FINDINGS}

The age brackets of the respondents was between twenty one and forty years with fifteen percent being between twenty one and twenty five years, thirty two percent being between twenty five and thirty years and fifty three percent being between thirty and forty years. The respondents were all from the private sector. Fifty percent of the people who responded worked in formal type of workplaces, the rest worked in semi-formal places and just a very minute six percent people worked in informal offices.

Mostly the informal and semi-formal office setups belonged to the people who worked in creative and arts related fields. Two of the people related to the creative field gave a detailed insight about the office environment and how they felt about it. These people had mixed reaction about their jobs, as according to them, they loved their jobs but also had the most hectic and over board schedules, which made them cranky and frustrated on some days and over the moon on other. According to them, most workers in their field sat in combined open spaces, so that they could interact easily and share and get views on their ideas more efficiently, without leaving their seats. This was a nuisance in some places, as the creative ideas got copied. Some creative design offices and the architectural firms let people sit where they wanted to give more boost in their thinking capability. The spaces designed for these sitting spaces were normally relaxing and comfortable and produced better results. The formal offices had closed cabins intended to isolate people from each other so that they were able to do more work without being disturbed. Individual offices belonged to the workers in the upper management. Eighty seven percent of the office workers did not have comfortable seating arrangement and ended up tired after the day, whereas twelve percent complained about a constant backache. Though almost all the employees liked their own sitting space, mostly because either it gave them a view to the outside world or they had customized their spaces with some personal belongings of their own. Some of the employees did not like their seating spaces, especially those who had seating near the entrances, washrooms or those who lacked privacy (figures 7 and 8).

On asking whether their office spaces were well ventilated, seventy percent responded that their offices

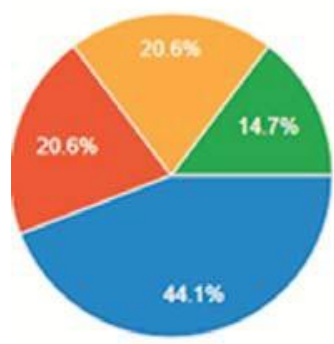

- Combined Open Space Cubicles Individual Office Anywhere you like

Figure 7: Seating arrangements in offices.

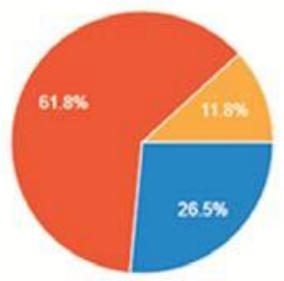

- Yes, very

Yes, Somewhat

No, I always end up breaking

Figure 8: Is the chair comfortable? 
were ventilated through artificial air conditioning only, whereas eighteen percent thought they had suffocating spaces and almost twelve percent claimed that their offices were well ventilated (figure 9). Forty two percent of the respondents claimed that they had control of the micro temperature, though thirty four percent of the offices were centrally air-conditioned. About forty seven percent of the offices caught daylight which did not hamper the indoor temperatures, whereas thirty five percent of the office workers did not see the sun throughout the day (figures 10 and 11).

About fifty percent of the respondents were comfortable with their workplace. Almost the same percentage claimed that their comfort depends on several other things. Just twenty percent of the offices were designed by interior designers, whereas most offices (i.e. about forty eight percent) used the space only as per need and did not care about the design according to the user's comfort. Almost fifty percent of the office workers claimed that they barely had enough space to walk and move around, out of which twelve percent claimed that they bumped into things while moving. Though fifty percent claimed that their office spaces were relaxing and soothing, the rest found their office spaces chaotic (figures 12 to 14).

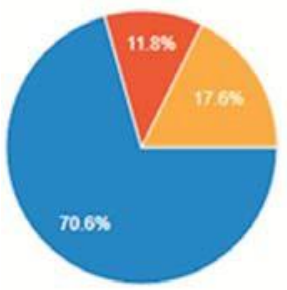

- Yes, Artificially, through air conditioners - Yes, Through Natural Air No, Sometimes its suffocating - We don't have airconditioners nor the area is well ventilated

Figure 9: Is your office well ventilated? November 2016.

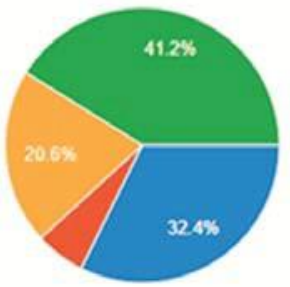

Admin/ centrally air conditioned - Myboss

I have it and I decide for other

- Everyone has their own micro area controls

Figure 10: Who has the control of the room temperatures?

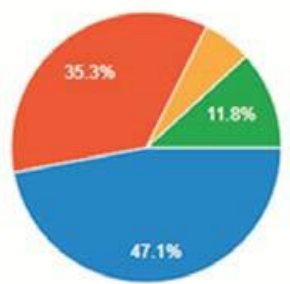

- Yes, its well lighted through day light - No, we never see the sun in the office Somewhat sunlight enters but it makes the environment hot

- Somewhat sunlight enters but it does not hamper the ventilation is well ventilated

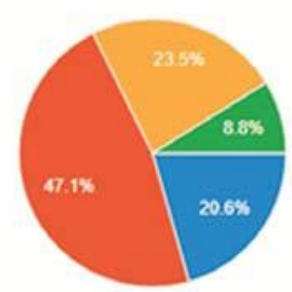

- Yes

No, its just space using

I have no idea, but it seems to be designed

- I have no idea, but it does not seems to be designed

Figure 12: Is your office designed by an interior designer?

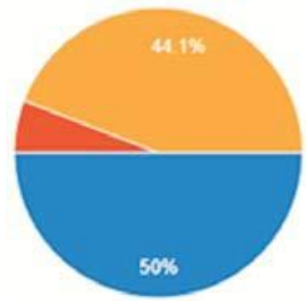

- Yes

No

Depends on the day or situation

Figure 13: Do you feel comfortable at your workplace?

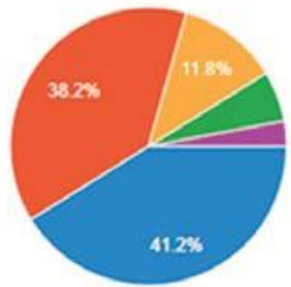

Yes, I like to stretch and walk around fo relaxation

Yes, enough to move around for work

No, I always bump into things

No, It's quite jammed pack

It doesn't apply to my kind of job i guess

Figure 14: Do you have ample space to walk around the office comfortably?

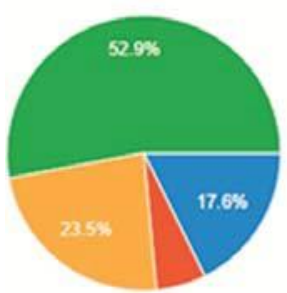

- Yes, but I never get time for it

Yes and we can take small breaks to avail them

No, but would an indoor game at the huddle room count?

- No, but we often team up and play online games

Figure 15: Does your office have a gaming zone or a gym?

None of the offices from the above surveyed group had a gym or a gaming zone for their workers relaxation, but about fifty percent of the workers played online and indoor games in their break hours (figure 15). About sixty percent of the respondents worked overtime when needed, which happened almost twice a week, and twenty percent had a constant overtime requirement which they considered extended office hours only. Interestingly, more than seventy five percent of the office workers were not paid overtime, though they sacrificed their family times for it. The survey also found that mostly office workers did not have

Figure 11: Does sunlight enter your office? 


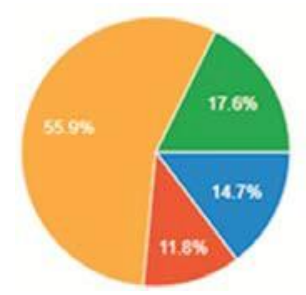

Figure 16: Does your workplace have a relaxation room?

any relaxation rooms except for the doctor's clinic. The artist's studio had napping spaces in the workplace (figure 16). This was not because they were being given a relaxation time or an extra leverage, but because they had double duties and needed breaks.

Just eighteen percent offices had green or open spaces which were visible from the seating areas, though twelve percent did have a green space at the entrance only. The rest of the seventy two percent of the office had no green spaces, though some potted indoor plants were placed (figure 17). Eighty five percent of the office workers took tea breaks whereas about thirty percent moved around and got some relaxation in tea breaks, though twenty five percent of them took tea break on their seats (figure 18). Almost all the workers found their office space smaller in size as per their need and thought the designs were of average to poor quality. The lighting system in the offices were generally good, though they were artificially lit and even if the daylight did enter the office, it was not enough for every day office tasks.

Most of the workers thought that their offices were in good locations with adequate security conditions, but their offices had poor parking spaces, which made it a daily stress to park before the office hours in a rush and reach office on time. Almost all offices had access to public transport, although only twenty five percent of the respondents thought that the public transport was either not easily available or a nuisance to get. About fifty five percent of the workers had good working relations with their colleagues, whereas thirty percent thought that good and bad people existed together so they had good relations with some and not with others, but the bad relations effected on their stress levels leading to over thinking and making things difficult.

About sixty five percent of the employees travelled more than six kilometers for work, out of which about

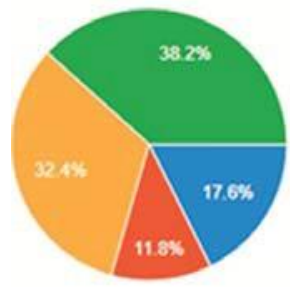

Yes, its very relaxing to see it from my

- Yes, we enter from a find garden but it's not visible from where I sit

No, can we count indoor plants as green

space?

No, there is nothing in the name of green

in my office

Figure 17: Does your office have green outdoor spaces?

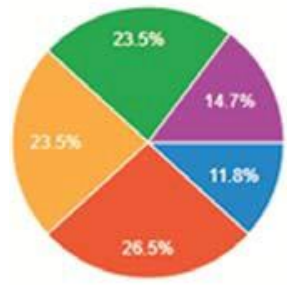

$$
\begin{aligned}
& \text { Very often } \\
& \text { Often } \\
& \text { Seldom } \\
& \text { I ask for tea/ coffee on my table, can't } \\
& \text { work without that } \\
& \text { I don't }
\end{aligned}
$$

Figure 18: How often do you take breaks?

thirty eight percent travelled more than twelve kilometers one way. Fifty six percent used car pools, twenty eight percent moved around with their bikes and twenty two percent travelled on public transport. Seventy percent of the travelers suffered from hectic travelling routine and disliked daily travel for this much time, with a lot of traffic jams, which they thought was one of the major reasons they felt frustrated. The ones who drove mostly complained of more stress due to traffic (about thirty three percent). Almost all the workers felt very tired, frustrated and stressed after work, out of which seventy five percent thought that it effected their daily lives and after office life, because they were never out of the "after office tired" syndrome. Forty percent of the employees thought that office load was enough for a day and they could not get involved in any outside activity after office hours, whereas twenty nine percent of the respondents indulged in outside activities with their families.

Almost thirty five percent of the office workers wanted to change their office furniture, whereas fifty percent thought that an addition to an open or green space would be quite relaxing. Forty four percent thought that the change in the overall design of their office could affect their stress levels and moods, whereas twenty percent thought that can only get better with better upper management policies, leaving twenty eight percent claiming that they had other things to stress over. 


\section{ANALYSIS}

According to the literature reviewed, one can conclude that it is an evident fact that architects have always thought about how the environment effects people. The fact cannot be denied that environment does affect people, whether in a negative or a positive manner. Taking the example of Villa Savoye, Architect Le Corbusier thought that the house was a healing machine, whereas it turned people sick. The environment of Villa Savoye did effect the inhabitants but in a negative way. Similarly Pruitt-Igoe was thought to be the epitome of Modern Architectural Determinism and was made as a very strong concept of urban living, community interactions and enclosed playgrounds intended to reduce criminal activities, but it was not successful and became a breeding ground for criminal activities.

With respect to this research and in the case of Karachi, office workers spend forty five to sixty percent of their days in office spaces which are mostly too crammed and more suitable for the expensive equipment than for the people who use them. If these situations are carefully studied and offices are designed according to the needs of the workers and the type of people using it, it will surely impact the behavior of the office workers on a positive note. Health, physical wellbeing and productivity should be the focus of the designs of offices with adequate ventilation, air quality, comfortable temperatures, ergonomics of furniture, green spaces, beautiful views, ambiance and ownership of spaces being the premium tools for design.

From the questionnaires it can be deduced that the average users of office spaces face a lot of stress and frustration, because of the social and physical conditions of these workers, but a sizeable unit of this comes from the environment of the offices which effects them directly. Particularly, office workers prefer green spaces in their offices as these spaces help them relax. The ventilation, temperature control and lighting also plays an important role in making the environment comfortable.

A common trend in Karachi is to ventilate the offices with artificial air conditioning, which is quite disastrous to health and the environment in the long run. Other than that, in the short term too, office workers face non-comfortable temperatures, sometimes they are under the flu zone because of the low temperatures or due to sitting constantly in a suffocating office they develop a reccurring headache. The temperatures must not be in super comfort zone that they effect the productivity of the workers, neither should they be too suffocating. The ability to control temperatures gives the workers enough authority to regulate it to their working comfort. It is also more feasible to let the workers personalize their spaces. Some offices can also have informal setups, which gives freedom to the workers to move according to convenience. These offices can have lounges and lobby seating that can be isolated or combined at will, with lots of green spaces, water bodies and connection with nature to enhance creative thinking. The term creative block is quite common amongst these workers. Sometimes creative office workers have been found to claim that they got an idea by only changing a mere seating arrangement.

In formal offices, the office designs should be according to the need of the people working in them. They should be given feasible breaks to relax. Some gyms, or gaming zones should be part of the design of offices to make the workers stress free. It is quite healthy and relaxing for an office worker to follow a proper break schedule, as it not only increases the productivity but also gives them a recharge to work better. Thus, it is suggested to take about seventeen minutes break after almost every fifty two minutes of work, as it turns out that to be more productive, one does not need to work more, but to work smarter with frequent breaks. Our brains are not made to work for eight hours continuously, so to be a smart productive worker one must take frequent breaks which is spent away from computers, emails and anything related to work and spent on activities such as walking, light exercise, power napping, yoga, tea, chatting with colleagues or even breathing in clearer air (Evans, 2014). To take these breaks, spaces should be designed within the offices (Evans, 2014).

Most of the workers in Karachi travel more than six kilometers for getting to their work place, which becomes very tiring, considering the amount of stress that is experienced on the roads for anyone who is either traveling through public or private transport. This again adds to the behavior of workers in the afterwork life, and it effects the daily productivity. It must be considered in the plans for the workers and their comfortability that a proper system of transportation is provided which is comfortable. Most of the companies that provide this facility claim that their 
workers are happier in their environment and female population prefers such jobs.

Thus, a clear understanding is needed by the employers to address the workers' health and wellbeing, not only to save their viable asset but to bring more productivity in their businesses. A deep environmental psychological study should be part of any start of the design of an office space to give the workers more strength in the offices, to design the space according to people's requirements and make it more adaptable by the users themselves. Work routines should be scheduled in a manner that no stress or frustration is accumulated from the work place. This not only helps to gain better productivity in a work place, but is also an asset for the company.

\section{CONCLUSIONS}

Considering the research questions of how different spaces influence cognition and if there is an ideal kind of architectural space for various kinds of thinking this research concludes that every space impacts upon its users. For architects and designers, the awareness that built environment influences health, wellbeing and productivity of their inhabitants is not new. Studies demonstrate clearly how poor air quality and lighting intensifies the number of sick days and can affect sleep of employees. Sitting spaces, their vicinity, the views which are seen from the space, along with how many breaks a person takes in working hours, all effect the behavior of a person. Creating good indoor air quality, thermal comfort, high quality views, daylight, good acoustics and aesthetical locations and amenities - all play a crucial role in creating a healthy and productive workplace. It all comes to the point that the connection between individuals and the building in which they are employed is vital and impacts on the cognitive behavioral changes of a person. Most of the businesses are missing this understanding and are overlooking the massive prospects this relationship can bring, specially when they are well equipped with all the relative data collected by their departments. In the context of Karachi, with the city being a busy metropolis and having many transit issues, it adds to the stress and frustrations of the workers. Furthermore, offices must include safety and security, as well as good conditional transportation facility from work to home and back. Offices must aim to design better constructive spaces that not only are comfort zones, but the long-lasting effects are in the form of more productive people with employees feeling relaxed in their workspaces, working peacefully and carrying the same positivity to their homes or after work lives. This is again necessary to avoid the mistakes from the past, emerging in the period of Modernism supporting the Architectural Determinism, where architects thought they were creating better spaces but in reality they were adversely impacting the users. For this it is essential that an office design is assisted with proper Environmental Psychology Department, which assists the design team and space typology that should be applied according to the need of the worker and the hierarchal system to produce strategies which are cognitive, supportive and effects the behavior of an employee in a constructive manner. 


\section{REFERENCES}

Alker, J., 2014, "Office Buildings are Key to Workers' Health, Wellbeing and Productivity", Viewed 13 September 2017, from https://www.theguardian.com/sustainable-business/2014/sep/24/office-building-design-worker-health-wellbeingproductivity\#top

Cameron, W. B., 1963, A Casual Introduction to Sociological Thinking, New York, Elsiever Architectural Press.

Evans, L., 2014, "The Exact Amount of Time you should Work Every Day", viewed 11 October 2017, from https://www.fastcompany.com/3035605/the-exact-amount-of-time-you-should-work-every-day

Golembiewski, J., 2014, "Building a Better World: Can Architecture Shape Behaviour?", viewed 30 September 2017, from https://theconversation.com/building-a-better-world-can-architecture-shape-behaviour-21541

Haslam, D. C. K., 2010, Designing Your Own Workspace Improves Health, Happiness and Productivity, Exeter, University of Exeter.

Lang, J., 1987, Creating Architectural Theory: The Role of Behavioral Sciences in Environmental Design, New York, Van Nostrand Reinhold.

Marmot, A., 2002, "Architectural Determinism- Does Design Change Behaviour?", British Journal of General Practice, Vol.24:(6), 192-206.

McLeod, S., 2014, "Cognitive Dissonance", viewed 30 September 2017, from https://www.simplypsychology.org/cognitivedissonance.html

Saarinen, T. F., 1976, Environmental Planning: Perception and Behavior, Boston, Houghton Mifflin Company. 